Página inicial: 493 - Página final: 512

Tipo de artículo: de investigación

\title{
Comprensiones del discurso normativo sobre inclusión educativa en Colombia.
}

Realizations of the regulatory discourse on educational inclusion in Colombia.

Recibido: enero 2016 Revisado: abril 2016 Aceptado: mayo 2016

Por: Edilberto Hernández González ${ }^{1}$ y Jesús S. Velásquez Restrepo ${ }^{2}$

\section{Resumen.}

Se presenta un análisis cualitativo al discurso normativo colombiano en torno a la Inclusión Educativa producido entre los años 1991 y 2013, se identifican conceptos, criterios e imaginarios que lo atraviesan, algunas relaciones entre dicho discurso y sus condiciones de emergencia. Se destaca, entre otros asuntos, que el discurso normativo colombiano con respecto a la Inclusión Educativa tiende a desconfiar de sí mismo, aspira a abarcar todas las realidades humanas, en este sentido homogeniza e idealiza los fenómenos.

\section{Palabras claves.}

Análisis del discurso, Inclusión educativa, Discurso normativo.

\begin{abstract}
.
A qualitative analysis to the Colombian regulatory discourse around Educational Inclusion, produced between 1991 and 2013, is introduced. Besides, some concepts, criteria, and imaginaries which cross it, as well as some relations between that speech and emergency conditions are identified. Among other issues, the Colombian normative discourse regarding Inclusive Education, which tends to distrust itself, is highlighted, and aims to encompass all human realities, which, in this sense homogenizes and idealizes the phenomena.
\end{abstract}

\section{Key words.}

Discourse Analysis, Educational Inclusion, Regulatory Discourse.

\footnotetext{
${ }^{1}$ Filósofo. Magister en Educación. Candidato a Doctor en Educación de la Universidad de La Salle, Costa Rica. Profesor de la universidad de San Buenaventura, Medellín. Contacto: Edilberto.hernandez@usbmed.edu.co edilbertohernandez09@gmail.com .

2 Químico Industrial. Magister en Educación de la Universidad Católica de Manizales. Docente Secretaría de Educación de Caldas. Contacto: jesusvelasquez2510@hotmail.com
} 


\section{Introducción.}

La inclusión es una perspectiva discursiva que toma cada vez mayor fuerza en el mundo, exhibiéndose como la posibilidad de construir una sociedad en la que se reconozcan y participen todos los ciudadanos, suprimiendo de las dinámicas sociales todo tipo de discriminación. En este proceso participa la educación como el pilar importante, con la pretensión de promover una cultura de inclusión al interior de la escuela. Al mismo tiempo, el concepto de Inclusión Educativa sugiere una concepción de la formación que permita no sólo la aceptación del otro, sino, su reconocimiento como sujeto de derechos.

El Estado colombiano no ha sido indiferente a estos propósitos y en su normatividad dice reconocer los derechos de todas las personas y adquiere el compromiso de lograr una atención educativa donde todos los colombianos sean incluidos. Con este propósito se han definido una serie de normas que promueven la inclusión de aquellas poblaciones históricamente reconocidas como minorias y quienes, además, se reconoce que han sido segregadas del sistema educativo.

No obstante, se puede notar, que, a pesar de la emisión permanente de normas, en muchos contextos escolares de nuestro país, siguen presentándose prácticas educativas enmarcadas en la inequidad, la discriminación y la exclusión. Lo anterior pareciera estar asociado a las diferentes concepciones, criterios, valoraciones y prejuicios que se presentan entre los distintos actores del sistema educativo, lo que genera interrogantes en relación con la capacidad de dicho sistema para provocar una correspondencia asertiva entre las políticas de Inclusión Educativa y prácticas escolares incluyentes.

En atención a esta problemática, se planteó el estudio que recoge en el presente artículo, el cual exploró el discurso oficial de la Inclusión Educativa, en particular su vertiente normativa. El estudio se realizó bajo la perspectiva del análisis crítico del discurso, propuesta por Van Dijk, (1999) \& (2009), perspectiva que posibilitó situar los distintos micro-discursos que configuran la normatividad colombiana, así como también, establecer sus correlaciones con el discurso promulgado por la UNESCO (2010) y ciertos hechos sociales que vienen a sustentar las particularidades del discurso de la Inclusión Educativa.

El estudio toma en consideración la normatividad emitida a partir de la Constitución de 1991 hasta el año 2013, y su exploración inicial parte de la identificación de los conceptos, criterios e imaginarios que configuran dicho discurso y, a partir de ellas, establecer algunas correlaciones entre el discurso de la Inclusión Educativa en Colombia y sus condiciones de emergencia, tanto en el plano nacional como internacional. En el nivel crítico-comprensivo, se acude a algunas concepciones teóricas contemporáneas, entre ellas, el enfoque de la alteridad, principalmente bajo la perspectiva e Carlos Skliar; el enfoque de las capacidades humanas propuesto por Martha Nussbaum y el enfoque de desarrollo humano desarrollado por Amartya Sen. Las reflexiones de estos autores contribuyeron notablemente en una comprensión amplia del fenómeno abordado en el estudio.

Finalmente, el análisis recopilado en este artículo se encamina a interrogar estructuras discursivas donde prima una visión global que homogeniza la diversidad de las realidades humanas y promueve prácticas educativas donde no se reconocen las necesidades particulares, y por el contrario se privilegia, en función de la igualdad de derechos, un apoyo uniforme a todos los niños, niñas y jóvenes, lo que termina por configurar modos más sutiles de inequidad. 


\section{Metodologia.}

Este estudio fue abordado desde un enfoque fenomenológico-hermenéutico, el cual permitió un acercamiento amplio y cuidadoso a las tramas epistémicas que le dan forma al discurso normativo sobre Inclusión Educativa en Colombia, a la vez que, algunas aproximaciones a los propósitos que dinamizan dicho discurso.

Cabe señalar que este enfoque se articula a una perspectiva más extensa como es la investigación cualitativa, visualizada por diversos autores como un horizonte efectivo cuando se pretende rastrear aspectos de la realidad social, en este sentido Galeano (2004) sugiere que "la investigación cualitativa cruza disciplinas, áreas de conocimiento y problemáticas. Lo que envuelve la investigación cualitativa es una interconexión de términos, conceptos y pre-supuestos, ofreciendo flexibilidad, esto permite modificarse según las necesidades de estudio" (p.78)

Volviendo al tema del enfoque fenomenológico-hermenéutico, este ofrece diversas vertientes, pero en el presente estudio se ha privilegiado la perspectiva de análisis crítico del discurso, desarrollada por el investigador neerlandés Teun Adrianus Van Dijk, cuya perspectiva se centra en la relación entre el discurso y los contextos socio-políticos, dado que, el contexto influye en el discurso tanto como el discurso en el contexto. Al respecto Van Dijk (2009), afirma: "Una vez que se puede influenciar las creencias sociales de un grupo, se pueden controlar indirectamente las acciones de sus miembros" (p. 166). Para este autor, el contexto en cierta medida, determina los modelos mentales conducentes a la representación de los aspectos relevantes de la interacción discursiva; así mismo destaca la naturaleza bidireccional del vínculo contexto-discurso, donde el discurso contribuye al cambio e influye en las situaciones sociales. (Van Dijk, 1999, p. 23-25).

Si bien Teun Van Dijk (1999), no ofrece una ruta metodológica para desarrollar un análisis del discurso, desarrolla algunos planteamientos que permiten dilucidar una manera particular de abordaje del discurso.

El análisis critico del discurso va más allá de los limites de la frase, de la acción y de la interacción e intenta explicar el uso del lenguaje y del discurso también en los términos más extensos de estructuras, procesos y constreñimientos sociales, politicos, culturales e históricos, además de proveer bases para explicaciones en varias direcciones de investigación, tiende singularmente a contribuir a nuestro entendimiento de las relaciones entre el discurso y la sociedad (p.152).

En esta misma corriente de análisis del discurso, se encuentra el lingüista Oswald Ducrot (1982), para quien todo enunciado tiene un determinado carácter y depende de las condiciones en que es empleado (p. 28). Otro lingüista que realizó importantes aportes a la comprensión moderna del lenguaje y por tanto de las teorías del discurso es John Austin, (1996) para quien "emitir una expresión es realizar una acción" (p. 47) Por su parte Norman Fairclough, (citado por Santander, 2011), describe el discurso como una forma de acción, y el análisis de éste, como una práctica social, es decir, una dinámica que permite realizar acciones sociales.

Si bien el enfoque propuesto por Teun Van Dijk, (1999); (2009), ha sido el enfoque metodológico principal del estudio, el análisis desarrollado se apoyó también en la perspectiva históricoarqueológica planteada por Michel Foucault (1969), en el sentido de cuidar las conexiones que se presentan entre los discursos y los contextos socio-históricos en que se producen. 
En La Arqueología del Saber, Foucault propone examinar la historia, buscando obtener una comprensión profunda de los significados y significantes presentes en el discurso, a este respecto dice:

E1 análisis del campo discursivo [...] se trata de captar el enunciado en la estrechez y la singularidad de su acontecer; de determinar las condiciones de su existencia, de fijar sus limites de la manera más exacta, de establecer sus correlaciones con los otros enunciados que pueden tener vínculos con él (p.45).

En otro texto afirmará, "una historia critica sería un análisis de las condiciones en las que se han formado o modificado ciertas relaciones entre sujeto y objeto en un tiempo determinando" (1994, p.2).

En este sentido, para el presente estudio, se ha establecido un contexto particular de análisis, referido en todos los casos a la realidad contextual colombiana y un intervalo temporal comprendido entre 1991 y 2013. Las estrategias metodológicas específicas, parten de la sistematización de los documentos oficiales que encarnan el discurso de la Inclusión Educativa en Colombia. El análisis se estructuró en tres niveles de comprensión, empleando matrices de sentido. La primera de ellas, permitió categorizar por fecha, tipo de documento, finalidad y ente gubernamental que lo emite, para tal fin se realizó una indagación exhaustiva en las páginas web oficiales colombianas, entre ellas, la del Ministerio de Educación Nacional, la Alcaldía Mayor de Bogotá y la Secretaria de Educación de Manizales, entidades que presentan amplios avances en materia de legislación en torno al tema.

El segundo nivel de análisis comprende la puesta en escena de las categorías primarias del estudio, esto es, los conceptos, criterios e imaginarios que atraviesan el discurso normativo de la Inclusión Educativa en Colombia. Para este momento se diseñó una segunda matriz, la cual facilitó el rastreo de las categorías primarias a través de los documentos que ofrecían un mayor acercamiento al concepto de Inclusión Educativa. Seguidamente se identificaron y caracterizaron una serie de categorías de segundo orden, para lo cual se rastrearon las proposiciones subordinadas, a los diversos conceptos de Inclusión presentes en los documentos analizados.

Esta dinámica metodológica culmina en el establecimiento de las condiciones para la realización de un análisis comprensivo propiamente dicho. Para tal propósito se retoman las categorias de primer y segundo orden, las cuales configuran las estructuras microdiscursivas, que a modo de punta de iceberg, ofrecen los indicios de las redes estructurantes que configuran el discurso de la Inclusión Educativa.

\section{Demarcación teórica.}

Hablar de Inclusión o de Exclusión es dejar constancia de ciertos fenómenos de desigualdad social; es mostrar las particularidades que se posen y el lugar que se tiene en la colectividad, acorde con los parámetros sociales que envuelven al individuo y a su conjunto; de esta manera se marca distancia, entre quienes son aislados e ignorados y quienes participan en las dinámicas sociales y se benefician de ella, en palabras de Skliar, (2009), “(...) los procesos de exclusión e inclusión acaban por ser muy parecidos entre sí, siendo entonces la inclusión un mecanismo de control que no es la contra-cara de la exclusión, sino que lo sustituye". (p.18) 
En términos históricos se puede indicar que la educación especial tiene sus inicios hacia finales del siglo XVIII y principios del XIX, con la creación de instituciones para la atención de personas con discapacidad, prolongándose hasta mediados del siglo XX (Aguilar, 2004, p. 4-10). A partir de esta época, con la promulgación de los Derechos Humanos en 1948, que los países miembros de la organización de las Naciones Unidas, promueven una serie de politicas que buscan integrar a las personas con discapacidades fisicas y cognitivas, en el sistema educativo regular.

Algunos países, entre ellos Colombia, crean instituciones con personal preparado para enfrentar determinados tipos de discapacidad, principalmente deficiencias cognitivas. Sin embargo, las discapacidades fisicas y las diferencias etno-raciales no son tomadas en cuenta para el ingreso a dichos establecimientos. Luego se generaron políticas conducentes a ofrecer lo que se llamó una educación especial para las personas con discapacidad, y vista la segregación que esta generaba, se pasó a la normalización e integración de las personas, en un ambiente menos restrictivo. Es así como, hacia 1980, se comienza a pensar en la incorporación de etnias y población con discapacidad y otros grupos minoritarios al sistema educativo, bajo un modelo de integración, con la expectativa de aceptación y atención a estos educandos de acuerdo a sus características, mas no a sus necesidades.

A partir de la Constitución Política de 1991 se genera un nuevo modo de pensar la educación en Colombia. Los nuevos enfoques tendrán su impacto en la educación especial, a punto que se reconoce "que su fin no consiste en curar o rehabilitar a los sujetos con déficit, sino en hacer que adquieran las habilidades, valores y actitudes necesarias para desenvolverse en los diferentes ambientes de la vida adulta" (Arnaiz, 2003, pp. 2-7).

Es por ello que el término Integración, será sustituido del discurso educativo, pues sugería que la meta era integrar a la vida escolar y comunitaria a quien estaba excluido; en adelante se empleará el término Inclusión, ya que según Arnaiz (1996, p.25), comunica más claramente y con mayor exactitud, que todos los niños necesitan estar incluidos en la vida educativa y social de las escuelas del barrio, y en la sociedad en general. (Granada, 2013, p. 52), citando a Booth y Ainscow (2002) ofrece una definición que apoya esta percepción: "la inclusión educativa como un conjunto de procesos orientados a eliminar o minimizar las barreras que limitan el aprendizaje y la participación de todos los estudiantes”.

\section{Politicas de inclusión en un contexto global.}

La vida personal y social, acontece actualmente, en el marco de un mundo altamente globalizado en términos económicos y culturales. En este contexto se observa el fuerte influjo de organizaciones internacionales como la ONU, la UNICEF y la UNESCO, quienes generan discursos auspiciados por las grandes potencias económicas, y que posteriormente son promovidos globalmente. En este discurso se establecen politicas incluyentes, en las que se reconoce que cada ser humano posee dignidad en sí mismo y merece igual consideración y respeto.

Bajo esta perspectiva, factores como: las tendencias sexuales, el estatus social, las ideologías, la etnia o situaciones personales derivadas de una discapacidad o sobredotación fisica, intelectual o sensorial, por lo menos en teoria, no representan un impedimento para la aceptación en la comunidad educativa. No obstante, la praxis muestra lo utópicas que resultan estas aspiraciones, puesto que aún no se logra generar una cultura de respeto por el otro, por lo que de la diversidad existente en la escuela y la falta de reconocimiento legítimo de las innegables diferencias es de donde surgen con frecuencia las desigualdades, 
las discriminaciones y las jerarquizaciones que son las que finalmente configuran el paradigma de la exclusión. A esto se refiere, de manera más precisa Skliar (2008):

...no se trata apenas de proclamar politicas de acceso universal a las instituciones, la entrada irrestricta de todas las personas con discapacidad a las escuelas. (...) En cierto modo parece quedar claro que hay que estar juntos en el sistema educativo, pero aún no disponemos de un pensamiento firme acerca del encuentro en sí, de la relación pedagógica como tal. (p. 5-6)

Los avances que las políticas sobre inclusión y los procesos incluyentes en la educación, aunque precarios, son significativos. Bernal, (2010, p. 2), citando a Ruiz (2009), afirma, que durante muchos años y hasta fechas recientes, era impensable que una persona con síndrome de Down pudiese aprender a leer y escribir. Alguien asumió el reto de enseñarles y hoy una gran cantidad de personas con este sindrome aprenden a leer y a escribir de forma comprensiva. Esto muestra cómo las oportunidades y los entornos pueden determinar el desarrollo de la persona.

El Informe Mundial de Seguimiento de la Educación para Todos elaborado por UNESCO (2010. p. 3-6), muestra que la marginación en la educación es el producto de una mezcla de desventajas heredadas, procesos sociales profundamente arraigados, dispositivos económicos injustos y politicas deficientes que afectan a varios grupos sociales entre los que podemos mencionar: Mujeres y niñas, Niños en zonas de conflicto, Minorías étnicas, Niños con necesidades especiales, Niños afectados por el VIH/SIDA, e Inmigrantes.

En el contexto colombiano, las politicas internacionales, han sido un marco inspirador para el surgimiento la nueva legislación en relación con la apropiación e implementación de prácticas de respeto a los derechos de las minorias en Colombia. En este sentido, desde hace más de dos décadas, nuestro país ha buscado la consolidación de un sistema educativo que propicie el acceso de todos a una educación de calidad sin ningún tipo de exclusión.

Los postulados de la Constitución de 1991, reconocen la diversidad propia del país y establece, en el Artículo 67, que la educación es un derecho fundamental y un servicio público con función social. Aunado a ello, los planteamientos de la Conferencia Educación para Todos (1990), la Conferencia Mundial de Salamanca (1994), y la 48 ${ }^{a}$ Conferencia Internacional de Educación (2008), han exigido al Estado una profunda transformación frente a la discapacidad, que incluye no sólo a las administraciones nacionales y locales, sino a las instituciones educativas, en particular.

Pese a esto, según Calvo, Colombia es un ejemplo de la dificultad para traducir las normas sobre la inclusión en prácticas pedagógicas inclusivas. Pues, de acuerdo con esta autora, la no escolarización de la población con discapacidad pasó de un $3 \%$ a un $8 \%$ en el período 1996-2001, considera además que, esta población no culmina la educación básica, ni alcanzan la educación media, tan solo el $0.8 \%$ de las personas con discapacidad han recibido educación especial. (Calvo, 2007. pp. 5-11)

Estas situaciones conducen a reflexionar en torno a dos interrogantes ¿está preparado el sistema educativo actual, estructural y conceptualmente, para asumir los propósitos de una educación inclusiva? ¿Existen adecuadas comprensiones acerca de las implicaciones de concebirnos como una sociedad inclusiva?. 


\section{Inclusión Educativa y Desarrollo Humano.}

Uno de los enfoques sobre desarrollo humano más reconocido es el propuesto por Amartya Sen, (2000), quien dentro de su concepción incluye la educación, junto con la sanidad, como factores claves en el desarrollo humano. Considera el desarrollo, como la ampliación de las capacidades de cada persona y sitúa a esta en el centro de su propia acción. (Maraña, 2010)

Amartya Sen, (2000), se refiere igualmente a las capacidades, en términos de vida humana, en lo que somos efectivamente capaces de hacer, lo que podemos permitirnos hacer, lo que tenemos como instrumentos para hacer y eso depende de la riqueza, de la educación, del tipo de sociedad en que se viva; en este sentido, los individuos no tienen razón para concebirse como receptores pasivos de los beneficios que ofrecen los programas de desarrollo, por el contrario deben participar en la creación e implementación de los planes de justicia social. (p. 19-28). Por otro lado, en la Conferencia Internacional de Educación, celebrada en Ginebra en noviembre de 2008, Amartya Sen, se refiere a la inclusión como

una experiencia social ampliamente compartida, en donde se requiere la participación activa de la sociedad por la igualdad generalizada de las posibilidades y las oportunidades que se ofrecen a los individuos en el plano individual, y por el logro de un nivel de bienestar elemental para cada uno de los ciudadanos. (ED/BIE/ CONFINTED, 2008, pp. 6-7).

Otra perspectiva que cobra especial relevancia en el estudio del tema de la Inclusión Educativa es el enfoque de las capacidades desarrollado por Martha Nussbaum, (2012) en el cual las capacidades se definen como las oportunidades para llevar una u otra clase de vida, al tiempo que expresa: "cuando las personas son respetadas como iguales, están libres de la intimidación, pueden aprender sobre el mundo, y están libres de necesidades acuciantes... (p. 152) Esta autora, a través de su enfoque ofrece una imagen general de la sociedad como un contrato orientado al beneficio mutuo; las personas obtienen algo de su vida en común que no obtendrían viviendo por separado, el cual sólo se da entre personas libres, iguales e independientes. (Nussbaum, 2007. p.34)

Un análisis de los postulados de Martha Nussbaum y Amartya Sen acerca del bienestar humano permite una comprensión del desarrollo que va más allá de la capacidad de obtención de bienes materiales. Para estos dos autores, el bienestar se refiere a lo que las personas pueden ser y hacer y, así poder elegir la clase de vida que se desea llevar. Según Vásquez (2015, p. 48), citando a Nussbaum y Sen, afirma que una adecuada calidad de vida parte del desarrollo de capacidades básicas, competencias y del desarrollo como persona, permitiendo afrontar los diferentes retos que la sociedad plantea. Estas perspectivas se presentan a la vez, como un enfoque de derechos, en tanto que garantizar estas capacidades es legitimar los derechos humanos, lo que representa, reconocer un mínimo respeto por la dignidad humana.

\section{Hallazgos y discusiones.}

La aproximación comprensiva a la Inclusión Educativa en su vertiente normativa, desde la perspectiva del análisis crítico del discurso, implicó dimensionar sus núcleos microdiscursivos y la manera como estos dialogan entre sí y con los discursos provenientes de diversos organismos internacionales. 
El presente estudio tuvo como punto de partida la realización de un inventario conformado por sesenta y seis documentos, los cuales constituyen la voz oficial en torno a la Inclusión Educativa en Colombia; de estos fueron seleccionas aquellos que constituyen la vertiente normativa, por lo tanto, el material analizado estuvo constituido por veintiocho documentos: diez Leyes de la República, once Decretos, una Resolución del Ministerio de Educación, cuatro Directivas Ministeriales y un Auto. Sumado a los anteriores se asumió la Constitución Politica de 1991, como referente normativo fundamental.

De manera particular la atención se centró en ocho normas, que ofrecían un mayor acercamiento al concepto de Inclusión Educativa, son ellas: Ley 115 de 1994; Ley 1098 de 2006; Ley 1346 de 2009; Ley 1618 de 2013; Decreto 470 de 2007; Decreto 366 de 2009; Auto 006 de 2009 y la Constitución Política de 1991.

\section{- Descripción de los hallazgos.}

Un primer aspecto evidenciado en el estudio refiere al hecho, de que en general el discurso de la Inclusión Educativa en Colombia, es posterior al año de 1990, lo que parece estar articulado a los objetivos de la Declaración Mundial sobre Educación para Todos celebrada en Jomtien, Tailandia en el año 1990. En la cual, gran parte de los gobiernos mundiales reiteraron su compromiso de asegurar la educación básica como "la base para un aprendizaje y un desarrollo humano permanentes sobre el cual los países pueden construir sistemáticamente nuevos niveles y nuevos tipos de educación y capacitación" (WCEFA, 1990. p. 158)

En el contexto nacional el discurso de la Inclusión Educativa, tiene como antecedentes los movimientos de renovación que se produjeron a finales de la década de los ochenta, momento en el que los distintos grupos revolucionarios colombianos conforman la Coordinadora Guerrillera Simón Bolivar. Ésta articulación de los grupos insurgentes, logran poner en primer plano la necesidad de un Estado que garantizara los Derechos Humanos y el bienestar de todos los colombianos, idea que tuvo gran impacto en todo el territorio. Estas iniciativas logran concretarse en la Asamblea Nacional Constituyente de 1991, con el apoyo delos movimientos estudiantiles de la época y la apertura democrática del recién electo presidente Cesar Gaviria. (Medina, 2010) En este proceso también cumplirá un importante papel el Movimiento 19 de abril (M-19), recientemente reintegrado a la vida pública.

Ahora bien, acorde con las categorías previamente definidas para este análisis del discurso normativo de la Inclusión Educativa, se pudo establecer una serie de categorías de segundo nivel, las cuales configuran su estructura discursiva. Es así como se pudo evidenciar que el discurso normativo de la Inclusión Educativa en Colombia está articulado alrededor de las categorias que se describen a continuación.

- Calidad: La Constitución Política de 1991, responsabiliza al estado de la calidad educativa (Art. 67), al tiempo que la basa en el respeto y el desarrollo de la identidad cultural para los grupos étnicos (Art. 68). La Ley 115, compromete al Estado, la sociedad y la familia en la educación (Art. 4) y determina que la formación técnica en actividades agrícolas, pecuarias, pesqueras, forestales y agroindustriales es la base de la calidad de vida de los campesinos (Art. 64). La Ley 1618 considera la calidad educativa como derecho de las personas en condición de discapacidad o con necesidades educativas especiales (Art. 11, Inc. 1b), a la vez que considera que la rehabilitación mejora la calidad de vida para esta población (Art. 2, Inc. 7). La Ley 1098, hace garante al estado de la calidad educativa desde el nacimiento (Art. 41, Inc. 17). El Decreto 470, al igual que la Ley 1618, establece el derecho de las personas 
discapacitadas o con necesidades educativas especiales a una educación de calidad, a la vez que responsabiliza a las instituciones de la restitución de dicho derecho (Art. 11).

- Derechos: esta categoría fue identificada en la mayoría de los documentos. La Constitución Política se refiere a esta categoría, dentro de los criterios de igualdad para todas las personas (Art. 13), sin distinción de géneros (Art. 43); también determina que la educación es un derecho para todas las personas (Art. 67), incluyendo los grupos étnicos (Art. 68), siendo éstos fundamental para los niños (Art. 44), referencia igualmente la protección y formación integral de los adolescentes (Art. 44). La ley 115, lo expresa como fundamento de la educación (Art. 1), haciendo referencia al respeto por los derechos de los demás (Art. 5). La Ley 1098, determina el goce de los derechos de los niños, niñas y adolescentes desde la concepción (Art. 17), incluida una educación de calidad (Art. 28), y una etno-educación para estos, cuando pertenecen a grupos étnicos (Art. 41, Inc. 22); también se enuncian algunos derechos en educación y salud para las personas en condición de discapacidad (Ley 1098, Art 36, Inc. 2). La ley 1346, se refiere a esta categoría llevándola al ámbito de los derechos humanos bajo dos concepciones, una en la que se debe asegurar su goce pleno para las personas en condición de discapacidad (preámbulo y Arts. 1, 2, 4 y 24) y otra en cuanto a la formación en el respeto por estos (Art, 24, Inc. 1a). La Ley 1618, responsabiliza a las entidades públicas del ejercicio total y efectivo de los derechos de las personas con discapacidad (Art. 5). El Decreto 470, responsabiliza al Estado, la sociedad y la familia, según sus competencias, obligaciones y capacidades, del derecho fundamental a la educación de las personas con discapacidad (Art. 11). El Decreto 366, establece el derecho a una educación pertinente para la población en condición de discapacidad o talento excepcional. El Auto 006, asegura que el Estado conduce a anular o restringir los derechos y libertades de las personas con discapacidad, víctimas del desplazamiento (Cap. I.3.3.).

- Discriminación: La Constitución Política de 1991, expone que todas las personas tienen derechos, libertades y oportunidades sin importar el sexo, raza, origen nacional o familiar, lengua, religión, opinión política o filosófica (Art. 13), reafirmándolo frente al género (Art. 43). La Ley 1098, obliga al Estado a erradicar la discriminación de las prácticas pedagógicas (Art. 41, Inc. 20) igualmente a las instituciones educativas (Art. 42, Inc.12). La Ley 1346, presenta una definición de esta categoría en términos de igualdad, derechos humanos y libertades fundamentales (Art. 2). Por su parte a Ley 1618, expone que la garantía de los derechos de las personas con discapacidad depende, entre otras estrategias, de la no discriminación (Art. 1), y establece que la denuncia de cualquier acto discriminatorio contra esta población es deber de la sociedad (Art. 6, Inc. 7). El Decreto 470, reglamenta políticas públicas que sensibilicen a la comunidad educativa frente a la no discriminación de la población con discapacidad (Art. 11, Inc. i). El Decreto 366, ordena pertinencia en la educación y no discriminación para las personas con discapacidad y con talentos excepcionales (Art. 2). El Auto 006, por su parte, afirma que la indiferencia del estado profundiza la discriminación. (Cap. I.3.3.).

- Igualdad: La Constitución Política de 1991, expone la igualdad para todas las personas ante la ley (Art. 13), siendo clara en cuanto a derechos y oportunidades sin importar el género (Art. 43), y ordena al Estado promover y fomentar la igualdad de oportunidades a través de la educación permanente (Art. 70). La Ley 1618enfatiza en la igualdad de derechos de los niños y niñas con discapacidad (Art. 7). La Ley 1346 ordena que las personas con discapacidad pueden acceder a una educación primaria y secundaria inclusiva, en igualdad de condiciones con las demás (Art. 24, Inc. 2b) 
- Oportunidades: La Constitución política de 1991, ordena que todas las personas deben gozar de las mismas oportunidades (Art. 13), sin importar el género (Art. 43), ordena al estado promover y fomentar el acceso a la cultura con iguales oportunidades (Art. 70). La Ley 1618, asevera que la inclusión social asegura la igualdad de oportunidades (Art. 2, Inc. 2), al mismo tiempo afirma que una educación de calidad legitima oportunidades de progreso y prosperidad (Art. 11, Inc. 1b). El Decreto 470, determina que la inclusión ofrece igualdad de oportunidades para las personas con discapacidad (Art. 6, Inc. c). El Auto 006, explica que el Estado conduce a excluir a las personas desplazadas y discapacitadas de beneficios y oportunidades necesarios para mejorar sus condiciones de vida. (Cap. I.3.3.)

- Capacidad: la Constitución Política de 1991 (Art. 68), la Ley 115 (Art. 46), la Ley 1098(Art. 41, Inc. 21) y el Auto 006 (Cap. 1.5.1.1) se refieren a esta categoría desde la perspectiva de las capacidades excepcionales, estableciendo la obligatoriedad del Estado y del servicio público educativo frente a esta población, en tanto que la Ley 1618, hace referencia al derecho de las personas con discapacidad a lograr y mantener capacidades fisicas, mentales y vocacionales (Art. 9) yel Decreto 470, en cambio, habla del desarrollo de capacidades humanas, sociales, culturales y productivas en función de la inclusión social (Art. 9).

- Dignidad: la Constitución Política de 1991, reconoce la dignidad de todos los grupos culturales que conviven en el país (Art. 70). La ley 115, establece que la dignidad humana es el fundamento de la educación (Art. 1). La Ley 1098, obliga al Estado a garantizar un ambiente escolar respetuoso de la dignidad de los niños, niñas y adolescentes (Art. 41, Inc. 19), responsabiliza, además, a las instituciones educativas del respeto por la dignidad de toda la comunidad educativa (Art. 42, Inc. 3). La ley 1346, expresa la inherencia de la dignidad para las personas con discapacidad. Uno de los principios que rigen la ley 1618 , es la dignidad de las personas con discapacidad (Art. 3). El Decreto 470, se refiere a la dignidad de las personas en condición de discapacidad a partir de su inclusión (Art. 9). El Auto 006, por su parte, reconoce el arraigo de una "silenciosa y sutil marginación de las personas con cualquier tipo de discapacidad" que va en contra vía del principio de dignidad humana (Cap. 1.5.1-1).

- Discapacidad: la Ley 1098, se refiere a los derechos en salud y educación de los niños, niñas y adolescentes discapacitados (Art 36, Inc. 2), autorizando a los gobiernos Nacional, Departamental y Municipal, a celebrar convenios que garanticen tales derechos (Art. 36, párr. 3), obliga también al Estado a atender las necesidades educativas de estos y de quienes poseen capacidades excepcionales o están en situaciones de emergencia (Art. 41, Inc. 21), garantizando la asistencia cuando las condiciones de éstos lo exijan (Art. 41, Inc. 36). La Ley 1346, sostiene igualmente que las personas discapacitadas no participan en la sociedad en igualdad de condiciones con los demás (Preámbulo, Inc. e), esta ley ofrece una definición de persona discapacitada desde la perspectiva del sujeto (Art. 1) y expresa los compromisos estatales frente a los derechos y libertades fundamentales de los discapacitados (Art. 4), al tiempo que enfatiza en la Inclusión Educativa para los niños y niñas discapacitados (Art. 24, Inc. 2a). La Ley 1618, ofrece la misma definición de persona discapacitada que la ley antes citada (Art. 2, Inc. 1), igualmente hace responsables a las entidades públicas de la inclusión real y efectiva de las personas con discapacidad, mediante estrategias de rehabilitación basadas en la comunidad (Art. 5/8); también expone que el MEN es quien incorpora los criterios de Inclusión Educativa (Art. 11, Inc. 4d). Por su parte el Decreto 470 se refiere a la inclusión de personas con discapacidad como base de la equidad (Art. 6, Inc. c), además considera la educación como un derecho, por lo que las políticas públicas deben proteger, garantizar y promocionar los derechos de esta población (Art. 11) y sensibilizar a la comunidad educativa frente a los procesos de integración educativa (Art. 11, Inc. i). 
El Decreto 366, presenta una definición del estudiante discapacitado, cimentada en su desempeño (Art. 2), al tiempo que define los criterios administrativos para la atención de esta población (Art. 9) y responsabiliza al personal de apoyo pedagógico frente a los requerimientos diferenciales de los estudiantes con discapacidad o con capacidades o talentos excepcionales (Art. 14). Por su parte, el Auto 006, ofrece una definición de discapacidad a partir del entorno (Cap. III.9.1.1.) Expresa además, que la Constitución Política de 1991, no utiliza la terminología adecuada, de conformidad con los estándares internacionales para referirse a las personas con discapacidad (Cap. I.5.1.1.), también afirma que "la política de discapacidad se enmarca en el contexto de la protección de las personas y el manejo social del riesgo" (Cap. III.9.1.2.), se expone en esta norma que el MEN presenta reportes sobre atención educativa a personas desplazadas y en condición de discapacidad pero no se presenta información sobre la demanda y necesidades específicas de esta población, ni sobre acciones detalladas que permitan inferir una verdadera Inclusión Educativa. (Cap. III.18.).

- Necesidades: La Constitución Política de 1991, se refiriere a esta categoría desde condiciones que garanticen el acceso y la permanencia en el sistema educativo de los menores (Art. 67). La Ley 115, considera que desde los currículos mismos se debe atender los estudiantes con capacidades o talentos excepcionales (Art. 49); dice también que es responsabilidad del Estado y las entidades territoriales fomentar la educación para la rehabilitación y reinserción de las personas con carencias y necesidades de formación (Art. 71). La Ley 1098, obliga al Estado a atender las necesidades de niños, niñas y adolescentes, ya sean discapacitados, con capacidades excepcionales o en situaciones de emergencia (Art. 41, Inc. 21). La ley 1618, se refiere al respeto por las necesidades y posibilidades de las personas con discapacidad (Art. 9), al tiempo que expone el deber del MEN de definir la política y reglamentar el esquema de atención educativa a la población con necesidades educativas especiales (Art. 11). E1 Decreto 470, establece la necesidad de cobertura universal del servicio educativo (Art. 11). El Auto 006, se refiere a esta categoría desde las necesidades de los desplazados en condición de discapacidad (Cap. III.18.).

- Integración: la Constitución Política de 1991, se refiere a esta categoría en relación a los disminuidos físicos, sensoriales y psíquicos (Art. 47). La ley 115, por su parte, lo hace en relación con las acciones pedagógicas y terapéuticas de atención a los educandos en condición de discapacidad (Art. 46). La Ley 1618, lo hace en referencia a los niños, niñas y jóvenes con necesidades educativas especiales (Art. 11, Inc. 1a). Por su parte, el Decreto 470, relaciona esta categoría con la garantía de la calidad de vida escolar (Art. 11).

\section{- Discusión de los hallazgos.}

Entre los asuntos para destacar, está el hecho que el discurso normativo colombiano en torno a la Inclusión Educativa es movilizado desde loables intencionalidades, en tanto, que propende por delimitar los lineamientos para una atención adecuada hacia las personas en condición de vulnerabilidad, y presenta diferentes mecanismos para satisfacer las necesidades educativas de estos grupos poblaciones. Se trata además, de un discurso saturado de supuestos y diversidad de concepciones epistémicas. Diversidad que se presentan tanto al interior de algunas normas, y más aún cuando son correlacionas entre sí. Es de resaltar la ausencia de descripciones en torno a la calidad educativa, calidad de vida y necesidades educativas. Estas categorías se dan por hecho, suponiendo, quizás, que en el contexto colombiano hubiese un acuerdo al respecto de sus significados e implicaciones socio-educativas. 
Así mismo se pudo establecer que el discurso de la Inclusión Educativa, se encuentra estructurado desde lo idealmente esperado, y un tanto desligado de las realidades contextuales y epistémicas contemporáneas. Se plantea el logro de estándares educativos de los grupos que se reconocen como vulnerados, desligados de los intereses personales, de las expectativas de sus cuidadores, así como de las posibilidades del contexto. El discurso de la Inclusión Educativa, por tanto, idealiza las situaciones y deja por fuera los conflictos inherentes a la existencia.

Otra característica interesante del discurso normativo colombiano en torno a la Inclusión Educativa, está referido a la desconfianza en sus propios enunciados, lo cual se puede evidenciar, por ejemplo, en la continua reiteración con respecto a la restitución de derechos para algunos grupos poblacionales como: los discapacitados, los grupos étnicos, los menores con necesidades educativas especiales, los afectados por la violencia y la población rural, al punto de resultar recalcitrante en la protección y atención para las personas en condición de discapacidad. Ante esta insistencia y necesidad de clasificación constante de las personas y grupos, dice Carlos Skliar (2008) que éste puede volverse una política, a partir de la cual se marca a los diferentes, pues en muchos escenarios educativos se habla de procesos de inclusión, pero están obsesionados con la diferencia. El discurso normativo Colombiano sobre Inclusión Educativa, apuesta por una igualdad de condiciones y, al mismo tiempo, es insistente en señalar las diferencias de la población discapacitada frente a los demás.

Aunado a la tendencia clasificatoria, se presenta una serie de sub-categorizaciones al interior de varios de sus categorías estructurantes. La discapacidad, por ejemplo, se clasifica en: mental, cognitiva y fisica, esta última, a su vez, se divide en auditiva, visual, oral y motora. Por su parte, los grupos étnicos se clasifican en indígenas, afro-descendientes, raizales y población rom, mientras que los afectados por la violencia se clasifican en desplazados, desvinculados y desmovilizados. Este gusto por las clasificaciones, mantienen vigentes prácticas socio-culturales estigmatizantes, que en poco favorecen la integración y el reconocimiento integral del ser humano, más allá de sus eventuales singularidades. Al referirse a una persona, como ciega, sorda o bien bajo cualquier clasificación, se está participando en un sistema de totalización ontológica, centrada de forma exclusiva en un único aspecto, lo que termina por generar una reducción subjetiva, que poco contribuye al desarrollo personal y social de las personas.

Por tanto, el empeño en clasificar a la población, y emitir normas particulares para cada grupo, resulta en cierta medida una desconfianza en la Constitución Política de 1991, la cual enuncia los principios de igualdad (Art. 13) y el derecho a la educación (Art. 67) para toda la población, sin establecer ningún tipo de distinción.

Esta misma línea de desconfianza, se puede evidenciar la insistencia que se presenta con respecto a la sub-categoría de atención a la discapacidad; de los veintiocho documentos analizados, diecisiete de ellos establecen medidas en procura de la restitución de derechos a las personas en dicha condición. Aspecto que además, se puede considerar como el eje articulador del discurso normativo en torno a la Inclusión Educativa en nuestro país; de ello dan cuenta nueve Leyes, seis Decretos, una Resolución y un Auto.

Ahora bien, el discurso normativo analizado, no solo establece clasificaciones para la inclusión y la discapacidad, sino que además define criterios cuantitativos para determinados tipos de limitación. Este abordaje pone al descubierto las concepciones de ser humano que atraviesa dicho discurso, en este sentido parece persistir la idea de hombre-máquina, el cual es susceptible de ser reducido a mediciones funcionales. 
Por otro lado, este discurso sitúa en la discapacidad un diferenciador poblacional y enuncia un sujeto como discapacitado; de esta manera el discurso constituye grupos sociales y grupos de estudiantes normales y anormales. Bajo estas perspectivas las políticas de Inclusión Educativa, solicita que los docentes realicen prácticas de aula en correspondencia con las necesidades educativas de los diversos grupos, lo que parece estar fortaleciendo la idea entre el profesorado, de una exigencia imposible de cumplir, tal como lo plantea Skliar. (2008. p. 15)

Un caso particular es la manera como se ha definido el concepto de discapacidad. Mientras las Leyes 1346, 1618 y 167 la definen en función del sujeto, el Auto 006, lo hace en función del contexto, haciendo mención al riesgo de padecerla, al tiempo que precisa que el desarrollo normativo para la atención a los discapacitados es generoso. Hablar de la discapacidad en función del sujeto implica suponer que cierto grupo de seres humanos son diferentes, deficientes y por tanto anormales. Esta manera de enunciar al sujeto, centrando la atención en una de sus rasgos termina por producir más discriminación, pues se ignora el resto de sus capacidades. Por otro lado, cuando es definida la discapacidad en función del contexto, se entra a desconocer la relación existencial del ser humano con la naturaleza, y más particularmente se desestiman las posibilidades de adaptación.

El micro-discurso de la discapacidad, ya sea en la perspectiva del sujeto o del contexto, enuncia a un sujeto discapacitado, el cual es resaltado en sus carencias con respecto a los demás. Bajo este criterio, se podría afirmar, entonces, que la no discapacidad se refiere a un sujeto completo, en todas las categorias como persona, negando la incompletud que es una de nuestras condiciones como seres humanos. Lo que, en palabras de Skliar, (2009) "quizás se encuentre en el pensarnos como incompletud, en percibirnos como humanos en tanto y en cuanto somos incompletos, en que la incompletud, la finitud, el límite, la frontera, etc., son aquello que nos hace humanos". (p. 13)

Estas normas, aunque no todos sus contenidos están explícitos en la Constitución Política, se podrian inferir de ella. Este interés en la producción de documentos normativos, pareciera responder entonces, a una necesidad del Estado y de algunos grupos sociales de reafirmar su compromiso con estas poblacionales. Al respecto Martha Nussbaum, (2001, p. 12), sugiere que un marco normativo, requiere estar sustentado en el respeto mutuo y la reciprocidad, que las personas sean tratadas como fines y no como medios, como agentes y no como receptores pasivos de beneficios, prestando interés por las necesi $\neg$ dades de los otros.

La constante emisión de normas, conduce a hechos un tanto curiosos, como, por ejemplo, que la Ley 1618 de 2013, emitida por el Congreso de la República, es exactamente igual a la Ley 167 del año 2011, formulada por el mismo organismo. Por su parte la Ley 167 de 2011, a su vez, incluía gran parte del contenido de la Ley 1346 de 2009.

Por otro lado, cabe resaltar que las políticas de Inclusión Educativa en Colombia, se sustentan en los lineamientos de los modelos de integración que se aplicaron en décadas anteriores, tal como lo reconoce Arnaiz, (1996), con la diferencia que, en la actualidad, se superponen algunas exigencias que terminan por traducirse en lo que en palabras de Skliar, (2009, p. 18), sería dejar la escuela tal como era y como está, y de agregarle algunas pinceladas de deficiencia, algunos condimentos de alteridad anormal. Sólo eso, nada más que eso. 
Por último, resulta interesante destacar algunas de las particularidades del Decreto 366, el cual define límites a la aceptación y distribución de estudiantes en condición de discapacidad en las instituciones educativas, restringiendo la aceptación de la población con discapacidad cognitiva a un 10\% máximo del total de estudiantes en cada grupo (Art. 9 , Prgf. 1), a la vez que establece un valor inferior al $20 \%$ del total de matriculados en cada grupo para los estudiantes con discapacidad sensorial o con discapacidad motora (Art. 9, Prgf. 2). Este Decreto, que parece enmarcarse estrictamente en un enfoque economicista, define valores tanto para la organización de los grupos con estudiantes discapacitados y el número de docentes de apoyo que se pueden autorizar para la atención a la población con discapacidad cognitiva. Toda esta parametrización plantea interrogantes respecto a los reiterados enunciados de atención a toda la población vulnerable. ¿En quién se piensa cuando se define un porcentaje de discapacitados por grupo de estudiantes en un aula de clases? ¿Qué modos de relación con el otro se promueven desde este tipo de lineamientos? ¿Qué reconocimiento se le da a las capacidades creativas de comunidades?

\section{Conclusiones.}

El amplio número de documentos recolectados y el análisis de los conceptos, criterios e imaginarios presentes en los mismos, resalta la exuberancia, la reiteración, la idealización y la clasificación, presentes en el discurso normativo en torno a la Inclusión Educativa, características que responden, en gran medida, a los modos socio-culturales de abordaje de los fenómenos, en el contexto colombiano, en el cual se tiende a expresar el compromiso con ciertos grupos poblaciones a través de la emisión de normatividades.

Si bien el discurso normativo en torno a la Inclusión Educativa en nuestro país es extenso, en cuanto está representado por un amplio número de documentos, dicha extensión no se corresponde con su contenido. Se trata de un discurso reiterativo en unos mismos elementos, entre ellos, exaltar la fragilidad de algunos grupos poblacionales, lo que en cierta medida vulnera su propia dignidad, pues tal exaltación, termina por presentarlos como anormales, lo que viene a aumentar su dificultad de adaptación al entorno escolar; este énfasis en la vulnerabilidad puede terminar por traducirse en bajas posibilidades de potenciación de sus habilidades.

Aunado a lo anterior, se pudo evidenciar cómo la vertiente normativa del discurso oficial en torno a la Inclusión Educativa en Colombia expresa un especial ahínco en la discapacidad, mostrando ésta como la dificultad que tiene esta población para desarrollar determinadas actividades, acentuando la discapacidad desde enfoques bio-mecanicistas. Esta comprensión de lo humano, y de los procesos de enseñanza-aprendizaje, desconocen la amplitud e integralidad de las capacidades humanas. Quizás, una mirada centrada en el potencial de cada ser humano, singular y contextual, podrá dinamizar de manera más adecuada las capacidades de todos los actores de la escuela.

El contexto socio-político de la segunda mitad de la década de 1980, pese a encontrarse enmarcada por el conflicto armado y el narcotráfico, parece haber sentado las bases para la transformación del país, gracias al impulso de políticas sociales que tuvieran en cuenta a cada uno de los ciudadanos y ciudadanas, lo que desembocó en una legislación que tiene en cuenta las necesidades básicas de aquellos grupos poblacionales que históricamente habían permanecido en situación de marginalidad. 
Por otro lado, este estudio en torno al discurso normativo de la Inclusión Educativa en Colombia, también pudo establecer, que dicho discurso está en correspondencia con el interés por alcanzar los propósitos globalizadores que toman fuerza en la actualidad, en tanto que las políticas nacionales se diseñan buscando articularse a las exigencias de organismos internacionales, dejando de lado las particularidades socio-culturales propias de nuestro contexto, como lo es el potencial creativo y solidario de los comunidades, pues se encuentra poca correspondencia entre el discurso y las condiciones sociales, económicas y culturales propias del país. Frente a este aspecto se aportaron algunas percepciones que pueden conducir a una nueva concepción de la Inclusión Educativa, apoyada en diversos enfoques del desarrollo, pretendiendo generar provocaciones que conduzcan a nuevas investigaciones. 


\section{Referencias bibliográficas.}

Aguilar, G. (2004). Del Exterminio a la Educación Inclusiva: Una Visión desde la Discapacidad. $V$ Congreso Educativo Internacional. De la educación tradicional a la educación inclusiva (págs. 1-21). Costa Rica: Universidad Interamericana. Obtenido de http:/ / neuroharte.org/multimedia/documentos/Del\%20exterminio\%20a\%20la\%20 educaci\%F3n\%20inclusiva\%20una\%20visi\%F3n\%20desde\%20la\%20discapacidad. pdf

Arnaiz, P. (1996). Las escuelas son para todos. Siglo Cero, 27(2), 25-34.

Arnaiz, P. (2003). Los estudiantes con capacidad en una escuela para todos. Conferencia presentada en el centro nacional de recursos para la inclusión educativa.

Austin, J. (1996). ¿Cómo hacer cosas con palabras? Madrid: Paidós.

Bernal, C. (2010). Legislación que favorece la educación inclusiva. Obtenido de www.corporacionsindromededown.org:http://www.corporacionsindromededown. org/userfiles/Legislacion.pdf

Calvo, G. (2007). Colombia. La Dificultad para Concretar las Normas en Inclusión Educativa. Bogotá: OIE - UNESCO.

Ducrot, O. (1982). Decir y no decir. Barcelona: Anagrama.

ED/BIE/CONFINTED. (2008). La educación inclusiva: el camino hacia el futuro. 6-7. Ginebra.

Foucault, M. (1969). La Arqueología del Saber. Francia: Gallimard.

Foucault, M. (1994). Dits et écrits. París: Gallimard.

Galeano, M. (2004). Diseño de Proyectos en la Investigación Cualitativa. Medellín: Fondo Editorial EAFIT.

Ghiso, A. M. (2016). Profesionalización de pedagogos sociales en latinoamerica. Otra lectura a los tránsitos entre la educación popular y la pedagogía social. El Ágora USB, 16(1), 63-75. Obtenido de http://revistas.usb.edu.co/index.php/Agora/article/ view/2165/1893

Granada, M., Pomés, M., \& Sanhueza, S. (2013). Actitud de los profesores hacia la inclusión educativa. Centro de Estudios Interdisciplinarios en Etnolingüistica y Antropología Socio-Cultural. Papeles de Trabajo (25), 51-59. Obtenido de http://www.scielo.org. ar/pdf/paptra/n25/n25a03.pdf

Maraña, M. (2010). Cultura y desarrollo. Evolución y perspectivas (Vol. 1). UNESCO Etxea. Obtenido de http://www.unescoetxea.org/dokumentuak/Cultura_desarrollo.pdf

Medina, C. (2010). FARC-EP y ELN. Una historia politica comparada (1958-2006). Bogotá: Universidad Nacional de Colombia. Obtenido de http://www.bdigital.unal.edu. co/3556/1/469029.2010.pdf 
Nussbaum, M. (2001). Paisajes del pensamiento. La inteligencia de las emociones. Cambridge: Impresiones Universidad de Cambridge.

Nussbaum, M. (2007). Las fronteras de la justicia: consideraciones sobre la exclusión. Barcelona: Paidós.

Nussbaum, M. (2012). Crear capacidades. Propuesta para el desarrollo humano. Barcelona: Paidós.

Santander, P. (2011). Por qué y cómo hacer análisis de discurso. Cinta Moebio (41), 207224. Obtenido de http://www.cintademoebio.uchile.cl/index.php/CDM/article/ viewFile/18183/19048

Sen, A. (2000). Desarrollo como Libertad. Madrid: Editorial Planeta.

Skliar, C. (2008). ¿Incluir las diferencias? sobre un problema mal planteado y una realidad insoportable. Orientación y Sociedad, 8, 1-17. Obtenido de http://www.scielo.org.ar/ pdf/orisoc/v8/v8a02.pdf

Skliar, C. (2009). Poner en tela de juicio la normalidad, no la anormalidad: políticas y falta de políticas en relación con las diferencias en educación. Educación y Pedagogía, XVII(41), 11-22. Obtenido de http://aprendeenlinea.udea.edu.co/revistas/index. $\mathrm{php} /$ revistaeyp/article/view/6024

UNESCO. (2010). Informe de Seguimiento de la EPT en el Mundo. Llegar a los marginados. Francia: UNESCO. Obtenido de http://unesdoc.unesco.org/ images /0018/001865/186525S.pdf

Van Dijk, T. (1999). El Análisis Critico del Discurso. Barcelona: Anthropos.

Van Dijk, T. (2009). Discurso y Poder. España: Gedisa.

Vásquez Orjuela, D. (2015). Políticas de inclusión educativa: Una comparación entre Colombia y Chile. Educ.Educ, 18(1), 46-61. Obtenido de http:/ / educacionyeducadores. unisabana.edu.co/index.php/eye/article/view/4683/3853

WCEFA. (1990). Conferencia Mundial de Educación para Todos. Satisfacción de las necesidades básicas de aprendizaje. Nueva York: UNESCO. Obtenido de http:/ / www. unesco.org/education/pdf/JOMTIE_S.PDF 